\title{
Left bronchial isomerism, normal atrial arrangement and bronchomalacia mimicking asthma: a new syndrome?
}

\author{
A. Bush
} Left bronchial isomerism, normal atrial arrangement and bronchomalacia mimicking
asthma: a new syndrome?. A. Bush. (CERS Journals Ltd 1999.

ABSTRACT: Three children who presented with steroid-resistant airflow obstruction are described. They all had bronchomalacia in the setting of a rare visceral arrangement, namely left bronchial isomerism with normal atrial arrangement. Imaging and, in two cases, a normal residual volume in the face of severe airflow obstruction were diagnostic pointers to a nonasthmatic cause of wheeze. Although the association of these abnormalities may be coincidental, together they may constitute a new clinical syndrome.

Eur Respir J 1999; 14: 475-477.
Correspondence: A. Bush, Dept of Paediatric Respiratory Medicine, Royal Brompton Hospital, Sydney Street, London SW3 6NP, UK. Fax: 441713518763

Keywords: Bronchomalacia, fibreoptic bronchoscopy, left isomerism, steroid-resistant asthma, Williams-Campbell syndrome

Received: June 181998

Accepted after revision February 281999
Most children with asthma are successfully treated with moderate doses of inhaled corticosteroids. However, a small number do not respond even to high-dose therapy; under these circumstances, a full review of the pharmacotherapy, the environment, adherence to treatment and any psychological factors is mandatory. As part of that review, alternative diagnoses should be considered. This paper describes three children with apparent steroid-resistant asthma, one who was the subject of a previous case report [1] and two other cases, who had bronchomalacia with a very rare combination of other congenital abnormalities, including left bronchial isomerism with usual atrial arrangement. Isomerism can be defined as the absence of the normal lateralizing features which distinguish right and left-sided organs such as the lungs [2]. Thus, right bronchial isomerism (fig. 1) is characterized by two trilobed lungs each with a short main bronchus, and left bronchial isomerism by two bilobed lungs, each with a long main bronchus. The atrial arrangement, defined by the morphology of the pectinate muscles [2], almost invariably follows that of the bronchial tree.

The purpose of this report is, firstly, to draw attention to clinical and radiological signs which may allow future cases to a)

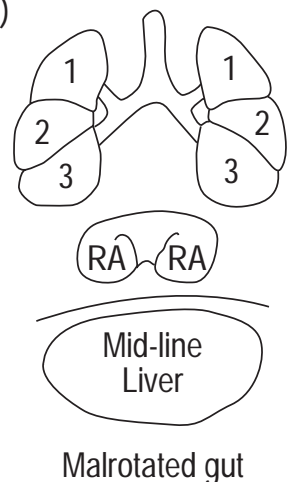

b)

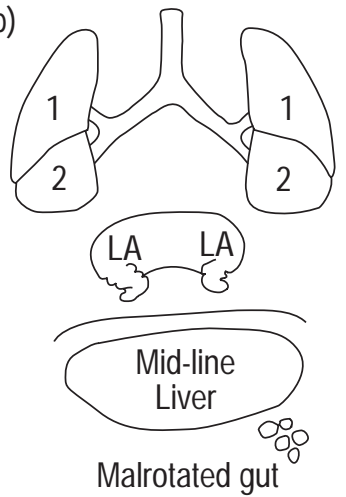

Fig. 1. - Features of: a) right; and b) left bronchial isomerism. The morphology of the right lung is trilobed, with a short main bronchus, and that of the left lung bilobed, with a long main bronchus. The differentiating features of the atrial morphology are discussed in detail in [2]. In addition to the intrathoracic abnormalities, gut malrotation and a mid-line liver are features of both isomerism sequences.Polysplenia is seen in $80 \%$ of cases of left isomerism, and asplenia in $80 \%$ of cases of right isomerism. RA: right atrium; LA: left atrium. be diagnosed early and, secondly, to suggest that this series of abnormalities may constitute a previously undescribed syndrome.

\section{Case reports}

\section{Patient 1}

A male with recurrent episodes of cough and noisy breathing from 5 months of age. He underwent ligation of a patient arterial duct at 22 months. He subsequently developed inspiratory and expiratory wheezing, which was resistant to oral and inhaled steroids. Lung function, when referred at age 12 yrs showed: forced expired volume in one second (FEV1) $33 \%$ of the predicted value, forced vital capacity (FVC) $65 \%$ pred, total lung capacity (TLC) $72 \%$ pred, residual volume (RV) $91 \%$ pred, and whole lung carbon monoxide transfer factor $(T \mathrm{~L}, \mathrm{CO}) 72 \%$ pred; $T \mathrm{~L}, \mathrm{CO}$ per litre of accessible lung volume $(\mathrm{KCO})$ was $135 \%$ pred. Fibreoptic bronchoscopy showed left bronchial isomerism, and bronchography showed a single discrete area of narrowing in the left-sided bronchial tree and multiple areas of malacia in the subsegmental bronchi in the right-sided bronchial tree. An echocardiogram confirmed normal atrial arrangement, and an abdominal ultrasound scan showed normal visceral positions with a single spleen. Fuller details of this child have been reported elsewhere [1].

\section{Patient 2}

This young female was well until 3 months of age, when she was admitted to the local hospital with a bronchiolitic illness; no viral pathogen was found at that time. The physical signs of an atrial septal defect (ASD) were found, and this diagnosis was confirmed on cardiac catheterization. She continued to wheeze. When seen at the Royal Brompton Hospital, she was noted to have inspiratory stridor as well as wheeze, but was very well. The question of a vascular ring was raised, but rigid bronchoscopy was inconclusive, no comment was made about bronchial situs. In retrospect, her airway tomograms showed evidence of left isomerism. At age 2 yrs, her ASD was closed. Six months later, her symptoms and signs were less. However, she never completely recovered, 
and had persistent wheeze and evidence of airflow obstruction, not responding to inhaled corticosteroids and short- and long-acting $\beta$-agonists. A diagnosis of postviral obliterative bronchiolitis was considered and she was re-evaluated at the Royal Brompton Hospital at age 15 yrs. At that time, lung function showed: FEV1 $56 \%$ pred, FVC $83 \%$ pred, peak expiratory flow rate (PEFR) 39\% pred, TLC 92\% pred, RV 101\% pred and $T \mathrm{~L}, \mathrm{CO} 96 \%$ pred. The flow/volume curve showed marked airway obstruction (fig. 2). A chest radiograph (CXR) and expiratory high-resolution computed tomography (CT) of the thorax showed no evidence of air trapping. Fibreoptic bronchoscopy and pulmonary angiography were performed. The bronchoscopy showed left bronchial isomerism, with diffuse bronchomalacia at all the segmental levels which could be examined, which was more severe on the left side. There was no evidence of a vascular ring. The angiograms confirmed a usual atrial arrangement with a bilateral long pulmonary arteries dividing into two branches. compatible with left isomerism. An abdominal ultrasound scan was normal. Her asthma medication (which had included fluticasone $500 \mu \mathrm{g}$ and salmeterol $50 \mu \mathrm{g}$, twice daily) was stopped with no deterioration in her severe airway obstruction. When off all treatment, she had a normal exhaled nitric oxide concentration ( 9.0 parts per billion (ppb), normal $<50$ [3]).

\section{Patient 3}

This young male was well until 3 months of age, when episodes of recurrent cough and expiratory wheeze prompted investigation. He was found to have a hypoplastic left lung on CT scanning. His subsequent course was of multiple admissions to hospital, during two of which he required prolonged positive pressure ventilation, despite treatment with inhaled and oral steroids at high dose. Further investigation included a 24-h $\mathrm{pH}$ probe, which revealed severe gastro-oesophageal reflux. He failed maximal medical management and was referred for fundoplication at age 4 yrs. Investigations at this time also included fibreoptic bronchoscopy, which showed left bronchial isomerism. The main airways were reduced in calibre, particularly on the left with diffuse malacia in the airway generations which could be seen. He also had laryngomalacia. He was too young to perform lung function tests. An echocardiogram showed normal atrial arrangement a structurally normal heart and a small left main pulmonary

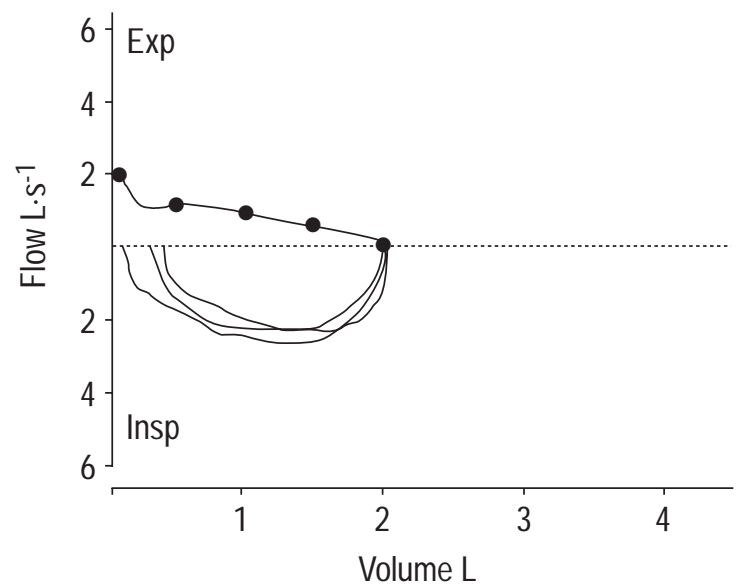

Fig. 2. - Flow-volume curves from case 2. There is evidence of widespread airflow obstruction, with a reduction in flow rates at all lung volumes in expiration, and some attenuation of inspiratory flow. artery. On fundoplication, his abdominal viscera were found to be normally positioned, with no evidence of polysplenia.

\section{Discussion}

This communication reports on three children who were initially thought to have asthma which was not responding to high-dose oral steroids. At fibreoptic bronchoscopy, each was found to have bronchomalacia, in the setting of left bronchial isomerism. In cases 1 and 2 , the clue to the alternative diagnosis was the finding of a low normal RV despite marked airflow obstruction, which is completely incompatible with the small airways disease characteristic of asthma. In each case, review of the imaging revealed abnormal arrangement of the airways, which had not previously been appreciated. Penetrated CXRs allow appreciation of airway morphology and calibre [4]. However, the delay in presentation until adult life of both the isomerism sequences $[5,6]$ and the right aortic arch with vascular ring [7] suggests that radiological signs of unusual large airway disease are often overlooked. Hence this report has practical implications for clinicians, as well as widening the spectrum of the associations of left isomerism.

Conventionally, bronchial anatomic arrangement can be the usual one (solitus), its mirror image (associated with primary ciliary dyskinesia [8]), and left and right isomerism. Anatomically, the morphology of the right bronchial tree is distinguished from that of the left by three features: the right main bronchus is shorter than the left; the lung is trilobed not bilobed; and (less usefully in routine practice) there is an eparterial bronchus, on the right [9]. Bronchial situs can be determined from a penetrated radiograph or airway tomograms [4], and atrial situs from echocardiography [10, 11]. Most commonly, there is concordance between atrial, bronchial and abdominal visceral arrangement [12], but this is not inevitably the case [13]. Left isomerism is associated with polysplenia, congenital heart disease [12], including abnormalities of the drainage of the caval and hepatic veins to the heart [14], and cardiac conduction defects [5, 15]. Abdominal visceral malrotation is another association, but, other than in the author's original report [1], abnormalities of airway function such as bronchomalacia have not to the author's knowledge been previously described.

Bronchomalacia may be congenital or acquired. Congenital bronchomalacia may be isolated, with generally a good prognosis, at least in the short term [16], and has been described in association with other congenital abnormalities [17] including connective tissue disorders, and Larsen's [18] and Fryn's [19] syndromes. Acquired bronchomalacia may be iatrogenic after treatment of neonatal respiratory distress [20], secondary to extrinsic compression by cysts [21] or the vasculature [22], complicating obliterative bronchiolitis after lung transplantation [23], and present after surgery for tracheo-oesophageal fistula. Williams and CAmpBell [24] described a syndrome of diffuse bronchomalacia affecting the second to the seventh generations of the bronchial tree. The occurrence in two siblings [25] and the very early onset of symptoms suggest a congenital aetiology. Whether the three children reported here represent a variant of Williams-Campbell syndrome or a separate entity cannot be determined without histological examination of bronchial cartilage which, for ethical reasons, was not practical in these children. However, the association of bronchomalacia with an exceptionally rare triad (normal atrial arrangement, left bronchial isomerism, normal abdominal viscera) seems very unlikely to have happened by chance, and suggests that this is truly a new syndrome. 
Diagnosis of bronchomalacia relies first on a high index of suspicion. If the diagnosis is suspected, it may be confirmed by fibreoptic bronchoscopy, bronchography or ultrafast CT [26]. Treatment includes removal of any predisposing factors, if practical. Medical treatment may be expectant, with consideration of respiratory support such as nasal continuous positive airway pressure or ventilation, particularly at night $[27,28]$. The diagnosis of bronchomalacia may not be easy, and, indeed, the flow/volume curves in the older children (see figure 2) might at first sight suggest that they had asthma after all. However, the lack of deterioration on stopping asthma treatment, and, in Case 2, the normal exhaled levels of nitric oxide, a marker of asthmatic airway inflammation [3], militates against this suggestion. A more likely explanation is that the weakness of the bronchial walls extended into the distal airway generations, beyond the reach of direct bronchoscopic inspection. Reduced flow at low lung volumes certainly implies disease of the small airways, but cannot be specific for the type of distal airway obstruction.

Surgical options include airway stenting, if there is localized disease [29, 30], or aortopexy for tracheomalacia or central bronchomalacia [31]. Currently, all three cases are being managed expectantly; the areas of malacia are thought to be too extensive for stenting and symptoms insufficiently severe to justify aortopexy.

In summary, three cases of bronchomalacia mimicking steroid-resistant asthma have been described, and are reported for two reasons. The first is that they illustrate at least two important clues that should alert clinicians to diagnoses other than asthma. These are, that a normal residual volume in the presence of severe airflow obstruction is never seen in asthma, and also an unusual bronchial arrangement (left isomerism) which can be appreciated from a penetrated chest radiograph. Secondly, the constellation of abnormalities reported together are so rare that their association with bronchomalacia may constitute a new syndrome, which broadens the spectrum of left isomerism sequence.

Acknowledgement. The author is grateful to R.H. Anderson for allowing use of the drawing in figure 1.

\section{References}

1. Lee P, Bush A, Warner JO. Left bronchial isomerism associated with bronchomalacia, presenting with intractable wheeze. Thorax 1991; 46: 459-461.

2. Anderson RH, Webb S, Brown NA. Defective lateralisation in children with congenitally malformed hearts. Cardiol Young 1998; 8: 512-531.

3. Byrnes CA, Dinarevic S, Shinebourne EA, Barnes PJ, Bush A. Exhaled nitric oxide measurements in normal and asthmatic children. Pediatr Pulmonol 1997; 24: 312-318.

4. Partridge J. The radiological evaluation of atrial situs. Clin Radiol 1979; 30: 95-103.

5. Wang TD, Tseng CD, Lee YT. Left isomerism in a middleaged woman with early-onset atrial fibrillation. Int J Cardiol 1997; 58: 269-272.

6. Winer-Muram HT. Adult presentation of heterotaxic syndromes and related complexes. J Thorac Imaging 1995; 10: 43-57.

7. Azarow KS, Pearl RH, Hoffman MA, Zurcher R, Edwards $\mathrm{FH}$, Cohen AG. Vascular ring: does magnetic resonance imaging replace angiography? Ann Thorac Surg 1992; 53: 882-885.

8. Elisasson R, Mossburg B, Camner P, Afzelius BA. The immotile cilia syndrome. A congenital ciliary abnormality as an etiologic factor in chronic airway inflammation and male sterility. N Engl J Med 1977; 297: 1-6.

9. Landing BH, Lawrence TK, Payne CV, Wells TR. Bronchial anatomy in syndromes with abnormal visceral situs, abnormal spleen and congenital heart disease. Am J Cardiol 1971; 28: 456-462.

10. Huhta JC, Smallhorn JF, Macartney FJ. Two dimensional echocardiographic diagnosis of situs. Br Heart J 1982; 48: 97-108.

11. Sharma S, Devine W, Anderson RH, Zuberbuhler JR. Identification and analysis of left atrial isomerism. $\mathrm{Am} \mathrm{J}$ Cardiol 1987; 60: 1157-1160.

12. Macartney FJ, Zuberbuhler JR, Anderson RH. Morphological considerations pertaining to recognition of atrial isomerism. Consequences for chamber localisation. Br Heart $J$ 1980; 44: 657-667.

13. Devine WA, Debich DE, Taylor SR. Symmetrical bronchial pattern with normal atrial morphology. Int J Cardiol 1988; 20: 395-398.

14. Guenthard J, Carvalho S, Anderson RH, Rigby M. Hepatic venous connection to a persistent inferior caval vein in left isomerism. Eur Heart J 1990; 11: 845-847.

15. Wren C, Macartney FJ, Deanfield JE. Cardiac rhythm in atrial isomerism. Am J Cardiol 1987; 59: 1156-1158.

16. Finder JD. Primary bronchomalacia of infants and children. $J$ Pediatr 1997; 130: 59-66.

17. Godfrey S. Association between pectus excavatum and segmental bronchomalacia. J Pediatr 1980; 96: 649-652.

18. Rock MJ, Green CG, Pauli RM, Peters ME. Tracheomalacia and bronchomalacia associated with Larsen syndrome. Pediatr Pulmonol 1988; 5: 55-59.

19. Strattion RF, Young RS, Heiman HS, Carter JM. Fryn's syndrome. Am J Med Genet 1993; 45: 562-564.

20. Miller RW, Woo P, Kellman RK, Slagle TS. Tracheobronchial abnormalities in infants with bronchopulmonary dysplasia. J Pediatr 1987; 111: 779-782.

21. Kosloske AM. Left mainstem bronchopexy for severe bronchomalacia. J Pediatr Surg 1991; 26: 260-266.

22. Robotin MC, Bruniaux J, Serraf A, et al. Unusual forms of tracheobronchial compression in infants with congenital heart disease. J Thorac Cardiovasc Surg 1996; 112: 415-423.

23. Novick RJ, Ahmad D, Menkis AH, et al. The importance of acquired diffuse bronchomalacia in heart-lung transplant recipients with obliterative bronchiolitis. J Thorac Cardiovasc Surg 1991; 101: 643-648.

24. Williams H, Campbell P. Generalised bronchiectasis associated with deficiency of cartilage in the bronchial tree. Arch Dis Child 1960; 35: 182-191.

25. Wayne KS, Taussig LM. Probable familial congenital bronchiectasis due to cartilage deficiency (Williams Campbell syndrome). Am Rev Respir Dis 1976; 114: 15-22.

26. Kao SC, Smith WL, Sato Y, Franken EA, Kimura K, Soper RT. Ultrafast CT of laryngeal and tracheobronchial obstruction in symptomatic postoperative infants with esophageal atresia and tracheoesophageal fistula. Am J Roentgenol 1990; 154: $345-350$.

27. Neijens HJ, Kerrebijn KF, Smalhout B. Successful treatment with CPAP of two infants with bronchomalacia. Acta Paediatr Scand 1978; 67: 293-296.

28. Miller RW, Pollack MM, Murphy TM, Fink RJ. Effectiveness of continuous positive pressure in the treatment of bronchomalacia in infants: a bronchoscopic documentation. Crit Care Med 1986; 14: 125-127.

29. Vinograd I, Filler RM, Bahoric A. Long-term functional results of prosthetic airway splinting in tracheomalacia and bronchomalacia. J Pediatr Surg 1987; 22: 38-41.

30. Filler RM, Forte V, Fraga JC, Matute J. The use of expandable metallic airway stents for tracheobronchial obstruction in children. J Pediatr Surg 1995; 30: 1050-1055.

31. Corbally MT, Spitz L, Kiely E, Brereton RJ, Drake DP. Aortopexy for tracheomalacia in oesophageal anomalies. Eur J Pediatr Surg 1993; 3: 264-266. 